\title{
ESTRATÉgIAS PARA A IMPLANTAÇÃO dO PROTOCOLO de IDENTIFICAÇÃó do PACIENTE EM UM HOSPITAL DE MÉDIO PORTE NO NOROESTE DO PARANÁ
}

\section{Strategies for the implementation of the Patient Identification Protocol in a medium-sized hospital in the northwest of Paraná}

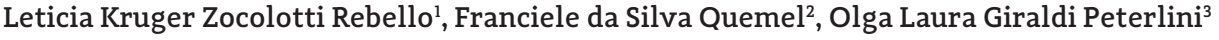

1. Enfermeira especialista em Gestão Hospitalar. e enfermeira do escritório da qualidade Associação Beneficente de Saúde do Noroeste do Paraná - Norospar.

2. Mestre em biotecnologia; Farmacêutica da Associação Beneficente de Saúde do Noroeste do Paraná - Norospar; Especialista em Saúde Pública, em Farmácia Clínica e Hospitalar e Farmacologia com Interações Medicamentosas.

3. Enfermeira e Mestre em Enfermagem; Chefe da Divisão de Ensino Superior da Escola de Saúde Pública do Paraná - 2018. Diretora de Educação da ABEn-PR - 2017-2019.

CONTATO: Leticia Kruger Zocolotti Rebello | Rua José Dias Lopes 4504 | apto 104 | Bloco 2 | Cond. Solar das Palmeiras | CEP 87502-270 | Umuarama | Paraná | Email: Ikzrebello@ gmail.com

COMO CITAR Rebello LKZ, Quemel FS, Peterlini OLG. Estratégias para a implantação do protocolo de identificação do paciente em um hospital de médio porte no Noroeste do Paraná. R. Saúde Públ. Paraná. 2019 Jul;2(Suppl 1): 31-37.

(c) COPYRIGHT Esta obra é disponibilizada nos termos da Licença Creative Commons - 4. 0

RESUMO A segurança do paciente é componente fundamental na qualidade do cuidado em saúde e tema prioritário na agenda da Organização Mundial de Saúde (OMS). A Portaria № 2.095/2013 institui os Protocolos básicos de segurança do paciente, dentre eles de Identificação do paciente que corresponde à meta número um da 
Política Nacional de Segurança ao Paciente, e o presente trabalho relata a experiência da implantação da identificação do paciente em um hospital de médio porte localizado em Umuarama, no noroeste do Paraná. Com a implantação do escritório da qualidade, os seis protocolos de segurança do paciente foram revisados e melhorados, dentre eles o Protocolo de Identificação, onde toda equipe da instituição foi capacitada sobre o que é, e a sua importância. Como resultados mostraram a redução do número de eventos adversos, principalmente os relacionados a medicamentos, sendo a primeira conquista do Núcleo de Segurança do Paciente-NSP desta instituição, recentemente implantado.

PALAVRAS-CHAVE: Segurança do paciente. Sistemas de Identificação de Pacientes . Gestão da Qualidade.

\begin{abstract}
Patient safety is a fundamental component in the quality of health care and a priority issue on the agenda of the World Health Organization (WHO). Ordinance N ${ }^{\circ} 2.095 / 2013$ dictates the basic protocols for patient safety, including the Protocol for the Identification of a patient, which is the first goal of the National Patient Safety Policy. The present study reports the experience of the implantation of patient identification in a medium-sized hospital in the city of Umuarama, in the northwest of the state of Paraná. With the formalization and creation of the Office for quality, the six patient safety protocols were revised and consequently improved, among them the Identification Protocol, with all the institution's team being trained on what this protocol is, and on its importance. The results showed a reduction in the number of adverse events, mainly those related to medication administration, being the first achievement of the Patient Safety Nucleus (NSP) of this institution, which has been recently implemented.
\end{abstract}

KEYWORDS: Patient Safety. Patient Identification Systems. Quality Management.

\title{
INTRODUÇÃO
}

A

segurança do paciente constitui um componente-chave para a qualidade assistencial nos últimos anos. Atualmente tem alcançado grande relevância diante das transformações no cenário moderno e competitivo dos sistemas de cuidados à saúde, decorrentes dos avanços científicos e tecnológicos nas áreas clínicas, ocorridos nas últimas seis décadas, da ampliação do acesso aos serviços de saúde e da difusão das informações em saúde no mundo globalizado?.
No Brasil há relatos de que a primeira iniciativa realizada no sentido de melhorar a segurança do paciente na organização hospitalar tenha sido feita por Odair Pedroso em 1935, ao idealizar uma ficha de inquérito hospitalar para a então comissão de Assistência Hospitalar do Ministério da Saúde?

Já em 2013 o Ministério da Saúde institui o Programa Nacional de Segurança do Paciente (PNSP) através da Portaria Ministerial n 529 de 2013, que tem por objetivo geral contribuir para 
a qualificação do cuidado em saúde em todos os estabelecimentos de saúde do território nacional promovendo e apoiando a implementação de iniciativas voltadas à segurança do paciente ${ }^{3}$.

Outra Portaria de 2013 aprova os Protocolos básicos de segurança do paciente, dentre eles o Protocolo de Identificação do paciente que corresponde à meta número 1 do $\mathrm{PNSP}^{4}$.

Alguns autores afirmam que a importância da identificação do paciente para a segurança nos serviços de saúde decorre não só do potencial para dar origem a erros sequenciais na cadeia de atendimento, mas também porque pode servir como um ponto de controle onde erros anteriores possam ser detectados e corrigidos, assim a grande relevância na implantação do uso da pulseira de identificação ${ }^{5}$.

Erros de descaso podem continuar ocorrendo se os pacientes não estiverem com a pulseira de identificação, ou se a pulseira não contiver a informação confiável para a identificação 5 .

A identificação do paciente tem duplo propósito: primeiro, determinar, com segurança, o indivíduo como sendo o legítimo receptor do tratamento ou procedimento; segundo, assegurar que o procedimento a ser executado é efetivamente aquele de que o paciente necessita ${ }^{6}$. Pode ser que a não identificação do paciente seja responsável por grandes números de eventos adversos que podem causar sérios danos à saúde dos pacientes, o que justifica um olhar atento a essa temática e ao desenvolvimento dessa prática no cotidiano de trabalho da enfermagem. Outra constatação importante deu-se com a pesquisa realizada em 2007 de autoria de Silva et al. que concluiu que "o emprego das pulseiras de identificação e a apropriada identificação no leito geram menor custo e, se utilizados efetivamente, contribuem para minimizar a ocorrência de administração de medicamentos a pacientes errados 8 ".

Em um estudo descritivo, foi constatado que a identificação do paciente atuou como barreira para identificar uma falha no processo relacionado a eventos adversos em 45\% das notificações e a quebra do protocolo foi responsável por 86\% das causas que levaram à ocorrência de eventos adversos ${ }^{9}$.

Ao considerar a relevância deste protocolo, o objetivo deste trabalho é relatar a experiência de implantação da identificação do paciente em um hospital de médio porte na cidade de Umuarama, localizada no noroeste do Paraná.

\section{ANÁLISE CONTEXTUAL}

A Cidade de Umuarama, situada no noroeste do Paraná, faz parte da $12^{a}$ Regional de Saúde, possui 04 unidades hospitalares, portanto uma referência na rede de atenção à saúde para os municípios vizinhos.

Neste contexto encontra-se um hospital sem fins lucrativos, com 120 leitos sendo 26 de unidade de terapia intensiva adulta, neonatal e pediátrica. É referência em gestação de alto risco e neurocirurgia de alta complexidade. Possui residência médica em pediatria, neonatologia, ginecologia e obstetrícia, cirurgia geral, anestesiologia, medicina de família e comunidade.

Atualmente o hospital possui um setor identificado como Escritório da Qualidade que é composto por 01 enfermeira e 01 médico como membros executores e com lideranças 
setoriais sendo membros consultores. Tendo por objetivo principal acompanhar os indicadores instrucionais e a partir de então propor implantação de melhorias a fim de aumentar a qualidade e a segurança dos serviços prestados. Já o núcleo de segurança do paciente (NSP) é uma comissão e está diretamente ligado ao Escritório da qualidade e é composto por equipe multidisciplinar que desenvolve ações principalmente relacionadas à farmacovigilância, tecnovigilância, hemovigilância e vigilância dos saneantes.

Em relação ao protocolo de identificação do paciente, este foi iniciado em 2014 de forma empírica, apenas como forma de cumprimento de legislação. No mesmo ano viu-se a necessidade de aquisição de máquinas impressoras de pulseiras para que o processo de identificação do paciente iniciasse no momento da abertura do atendimento do mesmo nas recepções da instituição. E assim foram adquiridas impressoras de pulseiras para as recepções, e as equipes envolvidas foram capacitadas.

No ano de 2017, com a formalização e criação do Escritório da Qualidade, os seis protocolos de segurança do paciente foram revisados e consequentemente melhorados, dentre eles: Identificação do paciente, prevenção de úlceras, segurança na prescrição, uso e administração de medicamentos, cirurgia segura, práticas de higiene das mãos em serviços de saúde e prevenção de quedas.

No Protocolo de Identificação beira leito, toda a equipe assistencial da instituição foi capacitada sobre o que é e a importância deste protocolo. Foi implantada também a identificação beira leito contendo nome completo do paciente, data de nascimento e os riscos, cuidados e procedimentos mais significantes para o paciente, a fim de alertar a equipe, familiares/ acompanhantes e visitantes sobre os mesmos, aumentando a vigilância e reduzindo eventos adversos melhorando assim a segurança do paciente.

Estas placas de sinalização beira leito de cuidados, riscos e procedimentos são placas retangulares e coloridas. Ao todo estão listados 44 riscos, cuidados e procedimentos como mostra o Quadro 1.

Na admissão do paciente no setor, a enfermagem após visita beira leito, e avaliação do paciente, providencia a impressão do nome completo e data de nascimento, e faz o levantamento dos principais riscos, cuidados e procedimentos. Todas estas identificações são fixadas beira leito em uma placa de acrílico. Estas informações também estão disponíveis no prontuário em formulário específico, para registro e sua formalização.

É importante salientar que estes riscos e cuidados são revisados e alterados constantemente pela equipe de enfermagem conforme alteração do quadro clínico e do processo de tratamento/ reabilitação do paciente. Podendo assim serem modificados tanto beira leito, como os registros em prontuários sempre que necessário.

Com a revisão do Protocolo de etiquetas padronizadas no serviço de nutrição e dietética e farmácia, foram instituídas etiquetas padronizadas contendo como elementos identificadores mínimos o nome completo e a data de nascimento, podendo ser acrescidos outros dados identificadores como no caso da pediatria, na qual as identificações possuem também o nome completo da mãe. É importante 
Quadro 1. Placas sinalizadoras beira leito de riscos e cuidados

\begin{tabular}{lll}
\hline Acesso Periférico - Flebite & Acesso Venoso Central & Alergia \\
\hline Cabeceira Elevada 45 & Cesárea & Cirúrgico \\
\hline $\begin{array}{l}\text { Compressa Fria - Gelo } \\
\text { Curativo }\end{array}$ & Controle de Lóquios & Controle Frequente Ssvv \\
\hline Dreno Suctor & Diálise Peritoneal & Dieta por Sondagem \\
\hline Em Capacete & Dreno Tórax & Dve \\
\hline Flebotomia & Em Processo Desmame Ventilador & Estimular Vo \\
\hline $\begin{array}{l}\text { Incentivo ao Aleitamento } \\
\text { Materno }\end{array}$ & Hemodiálise & Higienização das Mãos \\
Manter Grades Elevadas & Manuseio Restrito & Manter Contido No Leito \\
Mudança de Decúbito & Npt & \\
\hline Observar Glicemia & Parto Normal & Mmii Elevados \\
\hline Pós-Operatório & Pvc & Observar Curativo \\
\hline Precaução Respiratória & Repouso Absoluto do Leito & Picc \\
Sne - Cabeceira Elevada & Sng Aberta & Precaução de Contato \\
\hline Traqueostmomia & Ventilação Mecânica & Risco de Queda \\
\hline
\end{tabular}

Fonte: Elaborado pelos próprios autores

salientar também, que as puérperas recebem a sua pulseira de identificação e outra contendo dados do(s) recém(ns) nascido(s) evitando assim a troca de bebês. E ainda foi padronizada a identificação de cadáver com a implantação de uma etiqueta de identificação padrão.

Como forma de educação permanente o Escritório da Qualidade participa da integração dos novos colaboradores, capacitando-os sobre a importância da qualidade e segurança do paciente abordando de forma sistêmica os seis protocolos de segurança do paciente. São realizadas semestralmente ou sempre que necessárias as capacitações para as equipes de enfermagem mais especificas e aprofundadas sobre os protocolos, dentre eles a identificação do paciente.
A instituição também conta com uma enfermeira auditora interna que, em dias úteis e em horário comercial, visita todos os pacientes, e uma de suas atribuições é fazer a conferência beira leito da identificação do paciente. Caso o protocolo não esteja sendo cumprido, o colaborador ou a equipe responsável são notificados e em caso de recorrência até advertidos.

\section{RESULTADOS}

A implantação dos protocolos de segurança do paciente e a estruturação do escritório da qualidade revelaram um resultado positivo no decorrer dos meses, visto que foram nítidos 
o engajamento e adesão da maioria dos colaboradores ao protocolo e ainda a redução do número de eventos adversos principalmente relacionados à administração de medicamentos. Vale salientar, porém, que encontramos inúmeras barreiras que dificultaram esse processo, por exemplo, a resistência dos colaboradores na adesão e execução do protocolo e o não reconhecimento do corpo clínico em relação à efetividade do protocolo.

Constatou-se que a adesão efetiva ao protocolo nos setores da instituição tem como causas a falta de conhecimento/conscientização da cultura de segurança, o engajamento pessoal e coletivo e a comunicação na equipe de saúde. Assim, a enfermeira da qualidade e a enfermeira auditora interna vêm trabalhando sistematicamente com as equipes a fim de conscientizá-las sobre a importância da cultura de segurança, seja para ele enquanto profissional, seja para a instituição e enfim o paciente, ou seja, todos ganham.

Em constante capacitação ressalta-se que a equipe deve ser envolvida para o entendimento, a valorização e a conscientização da relevância da identificação do paciente, e que a participação da enfermagem é de fundamental importância na definição das estratégias que serão efetivas na implantação e melhoria das práticas. Para garantir a segurança do paciente faz-se necessário conscientizar todos os profissionais de que a prestação de cuidados adequados e sem danos é responsabilidade não só da enfermagem, mas de todas as equipes que interagem com o paciente.

O processo de implantação de novas práticas deve ocorrer de maneira colaborativa e construtiva, aliando o objetivo institucional de consolidar um atendimento com qualidade e segurança aos interesses e necessidades das equipes que trabalham na linha de frente do cuidado. A educação permanente, as atualizações, o aprimoramento e a reciclagem têm como objetivo incrementar os conhecimentos adquiridos na formação básica curricular e auxiliar na redução de falhas no processo de trabalho.

O NSP presente dentro dessa Instituição tem como desafio: verificar os protocolos já existentes e reavaliar a sua utilização/adesão, promover a capacitação permanente dos colaboradores, sensibilizar gestores, colaboradores e parceiros sobre a importância da política de segurança do paciente, e desenvolver e aplicar indicadores que determinem as urgências a serem trabalhadas.

\section{CONCLUSÃO}

O presente trabalho demonstrou a implantação, a importância e o engajamento dos profissionais no processo de identificação dos pacientes, com a implantação do protocolo de segurança beira leito, mesmo que tenha sido criado recentemente assim como o escritório da qualidade há pouco mais de um ano, tornase como um desafio constante na busca de contemplar as recomendações internacionais de segurança.

Esse relato de experiência contribuiu fornecendo evidências da utilização de pulseiras de identificação em pacientes internados na instituição e norteando o aprimoramento das práticas referentes a essa temática. Como demonstrado, sugere-se que seja realizado um monitoramento desse processo para levantamento de indicadores para acompanhamento do progresso das ações e comparações entre os diferentes momentos 
vivenciados pelo hospital, permitindo avaliar a consolidação de uma cultura de segurança na instituição.

\section{REFERÊNCIAS}

1. Árbol M. Moyano EMC, Pérez BC. Crespo MR. Eficacia de los programas de seguridad del paciente. Enferm Nefrol. 2016; 19(1):63-75.

2. Vasconcellos MFB. Acreditação hospitalar: ganho de qualidade nas instituições de saúde. [texto da internet] 2013. [Acesso em 19 out. 2018] Disponivel em: http://www.ebah.com.br/content/ ABAAAfWusAE/acreditacao-hospitalar

3. Brasil. Ministério da Saúde. Portaria $n^{0}$. 529, de $1^{\circ}$ de abril de 2013. Institui o Programa Nacional de Segurança do Paciente (PNSP). Diário Oficial da União 02 abr. 2013; Seção 1.

4. Brasil. Ministério da Saúde. Portaria nº. 2.095, de 24 de setembro de 2013. Aprova os protocolos de Segurança do Paciente. Diário Oficial da União, 25 set. 2013; Seção 1.

5. Smith AF et al. Wristbands as aids to reduce misidentification: an ethnographically guided task analysis. International Journal for Quality in Health Care. 2011; 23(5):590-9.

6. JCl. Metas Internacionais de Segurança do Paciente. Padrões de acreditação da Joint Commission International para hospitais. [editado por] Consórcio Brasileiro de Acreditação de Sistemas e Serviços de Saúde. 4. ed. Rio de Janeiro. 2011.

7. Howanitz PJ et al. Continuous Wristband Monitoring Over 2 Years Decreases Identification Errors. A College of American Pathologists Q-Tracks Study. Arch Pathol Lab Med. 2002; 126(1):809-15.

8. Silva $A E B C$ et al. Problemas na comunicação: uma possivel causa de erros de medicação. Acta Paul Enferm. 2007; 20(3):276.

9. Brito MFP. Avaliação do Processo de Identificação do Paciente em Serviços de Saúde. 2015. 227f. Tese (Doutorado) - Escola de Enfermagem de Ribeirão Preto, Universidade de São Paulo, Ribeirão Preto, 2015. 